\title{
Study of the Knowledge of Elementary School Health Teachers of Tehran City on How to Control Students' Teeth Injuries at School in
}

\author{
Vatanpour $\mathbf{M}^{1}$, Azimi $\mathrm{CH}^{2 *}$, Masoumi $\mathbf{Z}^{3}$ \\ ${ }^{1}$ Assistant Professor, Endodontics Dept,Dental Branch of Tehran, Islamic Azad University, Tehran, Iran \\ ${ }^{2}$ Post Graduate Student, Periodontics Dept,Dental Branch of Tehran, Islamic Azad University, Tehran, Iran \\ ${ }^{3}$ Dentist
}

\begin{tabular}{l}
\hline ARTICLE INFO \\
\hline $\begin{array}{l}\text { Article Type } \\
\text { Original Article }\end{array}$ \\
Article History \\
Received: Jul 2016 \\
Accepted: Nov 2016 \\
ePublished: Jan 2017
\end{tabular}

Keywords:

Knowledge,

Primary school teacher,

Dental injuries,

\begin{abstract}
Background and aim: Dental injuries are one of the common problems in children. Considering that nowadays, more attention is being paid to dental health and that school health teachers play a key role in the management of dental injuries, this research was designed with the aim of determining the extent of the knowledge of elementary school health teachers of Tehran city on how to control students' teeth injuries at school.

Materials and Methods: This research is a cross-sectional study. The questionnaires were given to 280 elementary school health teachers in Tehran city. Of the 280 questionnaires, 216 were answered (77.14\%). Data were collected and statistical analysis was performed using descriptive statistics methods and inferential statistics test in two study populations, chi-square independence and Spearman correlation coefficient with $95 \%$ confidence interval (CI).

Results: Receiving medical emergency training courses affected the responses to the questions regarding the maximum time to restore the teeth to their location $(\mathrm{p}=$ $0.001)$, and the most appropriate action in case of altered consciousness $(p=0.05)$. Receiving dental emergency training courses had no impact on the responses to any of the other questions $(p=0.231)$. According to Spearman correlation test results, there was a weak reverse significant correlation between age and the question regarding the most appropriate way to reposition the teeth in this case $(p=0.031$ and correlation coefficient $=-0.157)$, and between work experience and the question regarding distinguishing the tooth type $(\mathrm{p}=0.042$ and correlation coefficient $=-0.153)$.

Conclusion: the results indicated that the knowledge of these teachers is not adequate, and that there is a need for education regarding the management of dental injuries. Furthermore, there is no significant correlation between the responses to the questionnaire and receiving dental emergency training courses.
\end{abstract}




\section{Introduction:}

Knowledge of the complications caused by dental injuries plays an important role in controlling the outcomes; however, according to various studies, it seems that the knowledge of teachers in this regard is not adequate. For example, in a study by Caglar et al, knowledge regarding the type of storage medium for avulsed teeth was $17.9 \%{ }^{(1)}$ Another study in Hong Kong showed that when there is a need for replanting the teeth, only $5.4 \%$ of the teachers perform the replantation. ${ }^{(2)}$ In a study conducted in Iran, teachers' knowledge of dealing with dental injuries, particularly avulsed teeth, was $15.1 \%{ }^{(3)}$ Even the teachers have noticed this low percentage. In a study conducted in Singapore, $79 \%$ of the teachers were concerned with this issue. ${ }^{(4)}$ Dental injuries are one of the common problems in children, which impose a serious danger that potentially threats every child and can cause a lot of pain and discomfort. ${ }^{(5)}$ These injuries encompass damages to the teeth and the surrounding gingivae, and include subluxated, laterally luxated, and avulsed teeth, and crown and root fractures. ${ }^{(6-9)}$

Most dental accidents happen at the ages of 8 to 11 years. As a result, knowing how to manage dental injuries is very important in achieving treatment success. ${ }^{(1)}$ Studies in Scandinavia have shown that $22-30 \%$ of school children have experienced dental trauma to the permanent and deciduous teeth. It has also been estimated that over $50 \%$ of children are susceptible to dental injuries. Dental trauma may increase dental caries and periodontal diseases, and these two are considered as serious threats to dental health in childhood and adolescence with economic implications as well. ${ }^{(2)}$ Meanwhile, timely replacement of avulsed teeth or keeping them in proper condition will result in preservation of damaged teeth. Considering that nowadays, more attention is being paid to dental health and that school health teachers have a key role in the management of dental trauma, this study was designed with the aim of determining the extent of the knowledge of elementary school health teachers of Tehran city on how to control teeth injuries at school in 2014.

\section{Materials and methods:}

This research is a cross-sectional study. After translation and re-translation for validity $\operatorname{check}^{(4)}$, the questionnaire was approved by three endodontists. The questionnaire consisted of 7 items: 1- Case 1 question 1 (Distinguishing the tooth type: Deciduous or permanent, based on the age of the patient in the questionnaire).

2- Case 1 question 2 (The most appropriate action in this case).

3- Case 2 question 1 (the most appropriate action in case of avulsion).

4- Case 2 question 2 (Maximum time to restore the teeth to their location).

5- Case 2 question 3 (Best environment to keep the avulsed tooth).

6- Case 3 question 1 (The most appropriate action in case of altered consciousness).

7- Case 3 question 2 (The most appropriate way to reposition the teeth in this case).

The reliability of the questionnaire was determined by test-retest method in a time interval of two weeks, based on the responses of 20 school health teachers, and no significant differences were found $(\mathrm{p}=0.36)$. After this stage, the questionnaires were given to 280 elementary school health teachers of Tehran city in northern, southern, western and eastern regions selected by census in 2014. Of the 280 questionnaires, 216 were answered. After collecting the questionnaires, the data were analyzed to obtain the mean level of knowledge among the study population using descriptive statistics methods (frequency tables, graphs, and data calculation) and inferential statistics test in two study populations, chi-square independence and Spearman correlation coefficient with calculation of $95 \%$ confidence interval (CI).

\section{Result:}

The study was conducted on 216 female subjects who had answered the questionnaires. The tables were drawn based on data analysis. According to the results achieved from $\chi^{2}$ independence test, receiving medical emergency training courses affected the responses to case 2 question 2 (Maximum time to restore the teeth to their location) $(\mathrm{p}=0.001)$ and case 3 question 
1 (the most appropriate action in case of altered consciousness) $(\mathrm{p}=0.05)$. Accordingly, subjects who had received medical emergency training courses gave wrong answers to case 2 question 2 (74.3\%), and correct answers to case 3 question $1(90.7 \%)$. In the other cases, receiving the mentioned courses did not have any effect on the answers to the questions ( $\mathrm{p}=0.304)$. Also, receiving dental emergency training courses did not have any effect on the responses to all questions ( $p$ $=0.231$ ).

According to Spearman correlation test results regarding the variable of age and relevant questions in the questionnaire, there was a weak reverse significant correlation between age and the responses to case 3 question 2 (the most appropriate way to reposition the teeth in this case) $(p=0.031$ and correlation coefficient $=-0.157)$, which means that older people often provided the wrong answer to this question.

Table 1- Response percentage in teachers who had passed medical or dental emergency training courses

\begin{tabular}{|c|c|c|c|c|c|c|c|c|c|c|c|}
\hline & & \multicolumn{4}{|c|}{ Medical emergency training } & \multirow[t]{3}{*}{$\mathrm{P}$} & \multicolumn{4}{|c|}{ Dental emergency training } & \\
\hline & & \multicolumn{2}{|c|}{ No } & \multicolumn{2}{|c|}{ Yes } & & \multicolumn{2}{|c|}{ No } & \multicolumn{2}{|c|}{ Yes } & \\
\hline & & $\mathrm{N}$ & $\%$ & $\mathrm{~N}$ & $\%$ & & $\mathrm{~N}$ & $\%$ & $\mathrm{~N}$ & $\%$ & \\
\hline \multirow{3}{*}{$\begin{array}{l}\text { Case } 1 \text { question } 1 \\
\text { (distinguishing the tooth type) } \\
\text { (Deciduous or Permanent) }\end{array}$} & $\begin{array}{c}\text { Wrong } \\
\text { answers }\end{array}$ & 22 & 27.8 & 24 & 20.9 & 0.304 & 40 & 23.4 & 5 & 21.7 & 1 \\
\hline & $\begin{array}{l}\text { Correct } \\
\text { answers }\end{array}$ & 57 & 72.2 & 91 & 79.1 & & 131 & 76.6 & 18 & 78.3 & \\
\hline & $\begin{array}{c}\text { Wrong } \\
\text { answers }\end{array}$ & 42 & 57.5 & 69 & 65.1 & 0,348 & 98 & 62.0 & 14 & 66.7 & 0.812 \\
\hline Case 1 question 2 & $\begin{array}{l}\text { Correct } \\
\text { answers }\end{array}$ & 31 & 42.5 & 37 & 34.9 & & 60 & 38.0 & 7 & 33.3 & \\
\hline $\begin{array}{l}\text { (The most appropriate action in } \\
\text { this case) }\end{array}$ & Total & 73 & 100.0 & 106 & 100.0 & & 158 & 100.0 & 21 & 100.0 & \\
\hline $\begin{array}{l}\text { (the most appropriate action in } \\
\text { case of avulsion) }\end{array}$ & Total & 71 & 100.0 & 101 & 100.0 & & 151 & 100.0 & 21 & 100.0 & \\
\hline Case 2 question 2 & $\begin{array}{l}\text { Wrong } \\
\text { answers }\end{array}$ & 41 & 50.6 & 84 & 74.3 & 0.001 & 107 & 62.6 & 17 & 70.8 & 0.531 \\
\hline \multirow[t]{3}{*}{$\begin{array}{l}\text { (Maximum time to restore the } \\
\text { teeth to their location) }\end{array}$} & $\begin{array}{l}\text { Correct } \\
\text { answers }\end{array}$ & 40 & 49.4 & 29 & 25.7 & & 64 & 37.4 & 7 & 29.2 & \\
\hline & Total & 81 & 100.0 & 113 & 100.0 & & 171 & 100.0 & 24 & 100.0 & \\
\hline & $\begin{array}{c}\text { Wrong } \\
\text { answers }\end{array}$ & 30 & 39.5 & 51 & 48.1 & 0.291 & 70 & 44.0 & 10 & 43.5 & 1.00 \\
\hline Case 2 question 3 & $\begin{array}{l}\text { Correct } \\
\text { answers }\end{array}$ & 46 & 60.5 & 55 & 51.9 & & 89 & 56.0 & 13 & 56.5 & \\
\hline Case 3 question 2 & $\begin{array}{r}\text { Correct } \\
\text { answers }\end{array}$ & 67 & 83.8 & 107 & 90.7 & & 151 & 87.3 & 23 & 92.0 & \\
\hline $\begin{array}{l}\text { (the most appropriate way to } \\
\text { reposition the teeth in this case) }\end{array}$ & Total & 80 & 100.0 & 118 & 100.0 & & 173 & 100.0 & 25 & 100.0 & \\
\hline
\end{tabular}


Based on Spearman correlation test results regarding the variable of work experience and relevant questions in the questionnaire, there was a weak reverse significant correlation between work experience and the responses to question 1 from case 1 (distinguishing the tooth type) $(\mathrm{p}=0.042$ and correlation coefficient $=-0.153)$, which means that people with more work experience often had the wrong answer for this question.

Table 2-Evaluation of the most chosen options in responding to the questions

\begin{tabular}{lccc}
\hline Question & $\begin{array}{c}\text { Correct } \\
\text { option }\end{array}$ & $\begin{array}{c}\text { Most chosen } \\
\text { option }\end{array}$ & $\begin{array}{c}\text { Most chosen option's } \\
\text { percentage }\end{array}$ \\
\hline $\begin{array}{l}\text { Case 1 question 1 } \\
\text { (Distinguishing the tooth } \\
\text { type) }\end{array}$ & A & A & 71.8 \\
\hline $\begin{array}{l}\text { Case 1 question 2 (The most } \\
\text { appropriate action in this } \\
\text { case) }\end{array}$ & D & A & 47.2 \\
\hline $\begin{array}{l}\text { Case 2 question 1 (the most } \\
\text { appropriate action in case of } \\
\text { avulsion) }\end{array}$ & A & D & 34.7 \\
$\begin{array}{l}\text { Case 2 question 2 (Maximum } \\
\text { time to restore the teeth to } \\
\text { their location) }\end{array}$ & A & A & 33.3 \\
\hline $\begin{array}{l}\text { Case 2 question 3 (Best } \\
\text { environment to keep the } \\
\text { avulsed tooth) }\end{array}$ & C & C & 48.1 \\
\hline $\begin{array}{l}\text { Case 3 question 1 (The most } \\
\text { appropriate action in case of } \\
\text { altered consciousness) }\end{array}$ & B & B & 80.1 \\
\hline $\begin{array}{l}\text { Case 3 question 2 (The most } \\
\text { appropriate way to reposition } \\
\text { the teeth in this case) }\end{array}$ & B & B & 83.3 \\
\hline
\end{tabular}

According to Table 2, in case 1 question 1 (Distinguishing the tooth type), case 2 question 2 (Maximum time to restore the teeth to their location), case 2 question 3 (Best environment to keep the avulsed tooth), case 3 question 1 (The most appropriate action in case of altered consciousness), and case 3 question 2 (The most appropriate way to reposition the teeth in this case), the most chosen option is also the correct answer. According to the survey, $94 \%$ of the teachers felt the need for dental trauma training. Moreover, the percentage of the subjects who had received dental or medical emergency training courses was $12 \%$ and $56.9 \%$, respectively. The extent of the knowledge was $54.15 \%$ on average with $35.65 \%$ wrong answers on average.

To evaluate the test-retest reliability, the questionnaires were given to 20 teachers in two 10-day periods, and no significant differences were detected among the given answers $(\mathrm{p}=0.36)$.

Discussion:

Dental injuries are one of the common problems in children that cause severe pain and discomfort. ${ }^{(5)}$ Knowing how to manage these injuries is critical for successful treatment. ${ }^{(1)}$ Since health teachers play a key role in the management of dental injuries at schools, assessing their knowledge will have a great impact on preventing the complications caused by these injuries. This study was conducted on 280 primary school health teachers of Tehran city, where 216 of them participated and therefore, the response rate equaled $77.14 \%$, which is a significant percentage. Data analysis showed that there was no significant correlation between receiving dental emergency training and the extent of the teachers' knowledge. This could indicate that either these courses are not beneficial or the learners have not memorized them. However, in subjects who had received medical emergency training, there was a significant correlation between the responses to the question regarding the maximum time to restore the teeth to their location and the question regarding the most appropriate action in case of altered consciousness. A greater percentage $(74.3 \%)$ gave wrong answer to the question regarding the maximum time to restore the teeth to their location, which either means insufficient information rendition during medical emergency training or provision of false information in this respect.

Pithon et al. performed a study on the elementary school teachers' knowledge of dental trauma management. ${ }^{(10)}$ They found that nearly half of the teachers have satisfactory knowledge in this regard, and that women have higher knowledge than men. Moreover, being older, having more knowledge and experience, being experienced in such incidents or receiving first aid training courses had no effect on increasing the awareness. In the present study, there was no significant correlation between the teachers' knowledge and above-mentioned factors. However, a weak reverse correlation was detected, probably due to the fact that younger subjects with less work experience are more educated and thus have higher knowledge in this respect. Caglar et al. conducted a study in 2005 in two southern European cities to review the teachers' knowledge of dental trauma management. ${ }^{(1)}$ They concluded that more correct answers $(66 \%)$ were provided by Porto teachers regarding the proper storage medi- 
um for avulsed teeth, which is similar to the results of the present study (48\% correct answers). Moreover, a large percentage of the participants of the mentioned study gave correct answers to the question regarding the maximum time that the avulsed tooth can stay out. However, our research indicated a low ratio of $33 \%$ correct answers that shows lack of knowledge among the teachers. Finally, this study also considered improving the teachers' knowledge when necessary.

Singh et al. conducted a research where teachers with higher education level or with higher physical education level provided more correct answers regarding the storage media for avulsed teeth and the duration that these teeth can stay out. ${ }^{(11)}$ However, in the present study, we found no such significant correlation. In a study by Chan et al. which was conducted in Hong Kong in 2001, despite the large number of subjects who had participated in first aid training, the knowledge of dental trauma management was inadequate. ${ }^{(2)}$ For example, the knowledge regarding the best material for preserving, cleaning and transferring the avulsed tooth was only $9 \%$, and the most chosen option was ice. The authors believed that this answer was relevant to using ice in transferring and preserving body organs. However, in the present study, $48 \%$ of the participants chose milk. Moreover, in the mentioned article, no significant correlation was found between the knowledge and age of the participants, which is similar to the results of the current study (except for question 2 from case 3 , where there was a reverse significant correlation). Another survey was conducted in the mentioned study on the detection of deciduous or permanent teeth of 8-year-old children, where the majority of the subjects (47\%) answered the questions correctly. Similarly, a high percentage of the teachers in our study gave correct answers to the corresponding questions $(71.8 \%)$.

Fallahinejad et al. conducted a study in Tehran on this subject. ${ }^{(3)}$ The results showed no correlation between receiving first aid training and knowledge of dental trauma management, which is similar to the findings of the present study. In the above-mentioned study, $15.5 \%$ of the subjects were aware of tooth avulsion management, $42.7 \%$ were familiar with crown fracture, and
$68.5 \%$ were familiar with complete crown loss. The level of knowledge regarding avulsed teeth was approximately consistent with that in our study $(30.1 \%)$. However, in the cited study, a significant correlation was found between the teachers' knowledge and history of trauma in children $(\mathrm{p}<0.01)$, which was different from the results of the present study.

Al-Jundi et al. investigated the knowledge of teachers in the management of dental trauma. ${ }^{(5)}$ Similar to the present study, the results showed no significant correlation between age, work experience, receiving first aid training and the responses. In the same study, the response percentage and level of cooperation were high (86.3\%). Notably, in comparison to our study (71\%), fewer subjects responded to the question regarding determination of the tooth type (only 40.3\%). Sae-Lim et al conducted a comparable study on preschool teachers in Singapore. ${ }^{(4)}$ Similar to our study, $95 \%$ of the subjects felt the need for dental emergency training ( $94 \%$ in our study). In the cited study, a very small percentage of the subjects $(15 \%)$ were aware of the type of suitable storage media, which was not consistent with the findings of our study (48.1\%). Regarding the knowledge about permanent teeth replantation, subjects who had more work experience provided better answers $(p=0.003)$. Meanwhile, the present research did not find such significant correlation.

\section{Conclusion:}

According to the results of the present research, it seems that the knowledge of the assessed teachers is not adequate, and that there is a need for education regarding the management of dental injuries. Furthermore, there is no significant correlation between the responses to the questionnaire and receiving dental emergency training courses.

\section{Acknowledgments:}

The authors would like to thank the Dental research center of Tehran University of Medical Sciences and The AFM center of Iran University of Science and Technol- 
ogy for the laboratory work.

We are thankful to those who helped us in this article including research center of Islamic Azad University, Dental Branch of Tehran.

\section{Conflicts of Interest:}

the authors of this manuscript certify that they have no conflicts of interest regarding this research.

This study is based on student thesis no\# 24829 registered dental branch of tehran, Islamic Azad University.

\section{References:}

1.Caglar E, Ferreira LP, Kargul B. Dental trauma management knowledge among a group of teachers in two south European cities. Dent Traumatol 2005;21(5):258-62.

2.Chan AW, Wong TK, Cheung GS. Lay knowledge of physical education teachers about the emergency management of dental trauma in Hong Kong. Dent traumatol 2001;17(2):77-85.

3.Fallahinejad QM, Haghighatdoost E. Evaluation of primary school teachers' knowledge of dental traumas in student, Tehran-2003. J Dent Sci 2005; 22(special issue):21-25.

4.Sae-Lim V, Lim LP. Dental trauma management awareness of Singapore pre-school teachers. Dent traumatol 2001;17(2):71-6.

5. Al-Jundi SH, Al-Waeili H, Khairalah K. Knowledge and attitude of Jordanian school health teachers with regards to emergency management of dental trauma. Dent traumatol 2005;21(4):183-7.

6. Hall E, Hickey P, Nguyen-Tran T, Louie J. Dental Trauma in a Pediatric Emergency Department Referral Center. Pediatr Emerg Care 2016;32(12):823-6.

7.Fried I, Erickson P, Schwartz S, Keenan K. Subluxation injuries of maxillary primary anterior teeth: epidemiology and prognosis of 207 traumatized teeth. Pediatric dentistry 1996;18(2):145-51.

8. Trope M. Clinical management of the avulsed tooth: present strategies and future directions. Dental traumatology: official publication of International Association for Dental Traumatology 2002;18(1):1-11.

9.Gupta M. Intrusive luxation in primary teeth-Review of literature and report of a case. The Saudi Dental Journal 2011;23(4):167-76.

10.Pithon MM, Lacerda dos Santos R, Magalhaes PH, Coqueiro Rda S. Brazilian primary school teachers' knowledge about immediate management of dental trauma. Dental press J Orthod 2014;19(5):110-5.
11. Singh M, Ingle NA, Kaur N, Yadav P. Evaluation of knowledge and attitude of school teachers about emergency management of traumatic dental injury. J Int Soc Prev Community Dent 2015;5(2):108-13. 